\title{
Re: Shedding light on polypragmasy of pain after transurethral prostate surgery procedures: a systematic review and meta-analysis
}

\author{
Jeremy Yuen-Chun Teoh ${ }^{1} \cdot$ Marcelo Langer Wroclawski ${ }^{2,3}$. Steffi Yuen ${ }^{1} \cdot$ Bryan Cheng $^{4} \cdot$ Riccardo Bertolo $^{5}$. \\ Daniele Castellani ${ }^{6} \cdot$ Vineet Gauhar $^{7} \cdot$ Thomas Herrmann $^{8,9}$ (i)
}

Received: 2 March 2021 / Accepted: 6 March 2021 / Published online: 22 May 2021

(C) The Author(s) 2021

\section{Dear Editor,}

Persistent dysuria, pelvic pain or prostatodynia after transurethral prostate surgery is a classical example of a well recognised but poorly documented urological condition. Clinical presentation can be variable but the symptomatology is somewhat similar to the chronic pelvic pain syndrome $[1,2]$. The pain is usually bothersome and it tends to be persistent and refractory to medications. On the other hand, the etiology and pathophysiology are totally different, and the pain always occurs after transurethral prostate surgery. We believe its characteristics are clear and distinct enough to define it as the post-operative pelvic pain syndrome (PPPS).

Recently, we conducted a five-question survey to investigate the real world practice of managing PPPS after transurethral prostate surgery. The five questions covered the (1) current position of the respondent, (2) choice of treatment

Thomas Herrmann

thomas.herrmann@stgag.ch

1 Department of Surgery, S.H. Ho Urology Centre, The Chinese University of Hong Kong, Shatin, Hong Kong SAR, China

2 Hospital Israelita Albert Einstein, Sao Paulo, Brazil

3 BP, a Beneficencia Portuguesa de Sao Paulo, Sao Paulo, Brazil

4 Department of Surgery, United Christian Hospital, Kwun Tong, Hong Kong SAR, China

5 Department of Urology, San Carlo di Nancy Hospital, Rome, Italy

6 Department of Urology, IRCCS INRCA, Ancona, Italy

7 Department of Urology, Ng Teng Fong General Hospital, NUHS, Singapore, Singapore

8 Department of Urology, Spital Thurgau AG (STGAG), Pfaffenholzstraße4, 8501 Frauenfeld, Switzerland

9 Department of Urology, Hanover Medical School (MHH), Hannover, Germany modality for patients with PPPS after transurethral prostate surgery, (3) choice of anti-inflammatory medications for patients with PPPS after transurethral prostate surgery, (4) duration of treatment before being determined ineffective, and (5) treatment response based on a scale of 0-10, i.e., Out of ten patients, how many would actually respond to the treatment. The survey was primarily distributed via the \#UroSoMe Twitter platform [3]. A tweet about prolonged pain after transurethral prostate surgery was posted together with a link which directed to the Google Form survey platform. The survey was launched on 4th October 2020 and lasted for 6 weeks.

A total of 230 responses were received when the survey was concluded. Among the 230 respondents, $80.0 \%$ were urology consultants, $9.6 \%$ were urology fellows and $10.4 \%$ were urology residents in training. Regarding the choice of treatment modality (Table 1), the majority would offer anti-inflammatory agents $(88.7 \%)$, followed by alphablocker (42.2\%), gabapentin/pregabalin (40.4\%) and pelvic physiotherapy (39.6\%). For the choice of anti-inflammatory agents, the majority would offer oral non-steroidal and anti-inflammatory drugs (NSAIDs) $(81.3 \%)$, followed by NSAIDs suppository (17.0\%), oral corticosteroids $(17.0 \%)$ and intramuscular corticosteroids $(8.3 \%)$. About half of the respondents $(49.1 \%$ ) would try the treatment for 4 weeks before they determine it to be ineffective, but $27.4 \%$ would allow a prolonged treatment duration of 8-12 weeks. In their experiences, a mean of 5.9 out of ten patients would respond to the treatment being given.

Based on the above survey results, a recommendation on how to manage patients presenting with persistent dysuria/ pelvic pain/prostatodynia after transurethral prostate surgery was developed.

1. Rule out post-operative complications and organic causes such as urinary tract infection and capsular / bladder perforation. 
Table 1 Choice of treatment for patients with post-operative pelvic pain syndrome

\begin{tabular}{lc}
\hline & $\begin{array}{c}\text { Number of } \\
\text { responses (\%) }\end{array}$ \\
\hline Choice of treatment modality & \\
Anti-inflammatory medication & $204(88.7 \%)$ \\
Alpha-blocker & $97(42.2 \%)$ \\
Gabapentin / Pregabalin & $93(40.4 \%)$ \\
Pelvic physiotherapy & $91(39.6 \%)$ \\
Anti-cholinergic medication & $66(28.7 \%)$ \\
Antibiotics & $64(27.8 \%)$ \\
Phenazopyridine & $25(10.9 \%)$ \\
Beta-3 agonist & $23(10.4 \%)$ \\
Opioid & $20(8.7 \%)$ \\
Saw palmetto & $15(6.5 \%)$ \\
Sitz bath & $15(6.5 \%)$ \\
Baclofen & $13(5.7 \%)$ \\
Amitriptyline & $7(3.0 \%)$ \\
Low-intensity ESWT & $7(3.0 \%)$ \\
Serratiopeptidase & $4(1.7 \%)$ \\
Anti-fungals & $2(0.9 \%)$ \\
Tadalafil & $1(0.4 \%)$ \\
Choice of anti-inflammatory medications & \\
Oral NSAIDs & $187(81.3 \%)$ \\
NSAIDs suppository & $39(17.0 \%)$ \\
Oral corticosteroids & $39(17.0 \%)$ \\
Intramuscular corticosteroids & $19(8.3 \%)$ \\
Corticosteroids suppository & $9(3.9 \%)$ \\
Intravenous corticosteroids & $4(1.7 \%)$ \\
\hline
\end{tabular}

ESWT extracorporeal shock wave therapy, NSAIDs non-steroidal antiinflammatory drugs

2. Allow at least $8-12$ weeks for the patient to recover from surgery before confirming the diagnosis of PPPS.

3. Pelvic physiotherapy can be offered early given the noninvasive nature of the treatment $[4,5]$.

4. In addition, concomitant use of anti-inflammatory medications can be considered [6, 7]. Oral NSAIDS, NSAIDS suppository and oral corticosteroids are the preferred choice of anti-inflammatory medications.

5. If anti-inflammatory medications fail, other medications such as alpha-blockers and gabapentin / pregabalin can be considered at a later stage in a sequential manner $[6$, 7].

6. A minimum of 4 weeks and a maximum of 3 months should be allowed for the effects of each medication to take place [8-10].

Although this is just a short survey with five questions, it pinpoints the most important aspects in managing PPPS. The survey results represent the preferred management from urologists worldwide and can be considered an implied consensus regarding the best management of PPPS. In addition to this survey, a systematic review on PPPS after transurethral prostate surgery is currently under preparation. We hope to provide the 'best evidence' that we have so far and we believe it will be useful for providing guidance in in managing this condition. Although PPPS is not very common, it is certainly a very bothersome condition that deserves more thorough investigations. The optimal management of PPPS should be considered a priority and high-quality research work is urgently needed in the near future.

Author's contribution JYCT: project development, data collection, data analysis, manuscript writing. MLW: project development, data collection, manuscript writing. SY: data analysis, manuscript writing. BC: data analysis, manuscript writing. RB: manuscript editing. DC: project development, data collection, manuscript writing. VG: project development, data collection, manuscript writing. TH: project development, manuscript editing.

\section{Declarations}

Conflict of interest The authors declare no conflicts of interest.

Research involving human participants, their data or biological material Ethics approval was not required because no personal or clinical data were recorded.

Informed consent Consent was implied when the survey respondents agreed to participate in the survey.

Open Access This article is licensed under a Creative Commons Attribution 4.0 International License, which permits use, sharing, adaptation, distribution and reproduction in any medium or format, as long as you give appropriate credit to the original author(s) and the source, provide a link to the Creative Commons licence, and indicate if changes were made. The images or other third party material in this article are included in the article's Creative Commons licence, unless indicated otherwise in a credit line to the material. If material is not included in the article's Creative Commons licence and your intended use is not permitted by statutory regulation or exceeds the permitted use, you will need to obtain permission directly from the copyright holder. To view a copy of this licence, visit http://creativecommons.org/licenses/by/4.0/.

\section{References}

1. Doiron RC, Shoskes DA, Nickel JC (2019) Male CP/CPPS: where do we stand? World J Urol 37(6):1015-1022. https://doi.org/10. 1007/s00345-019-02718-6

2. Drach GW, Fair WR, Meares EM, Stamey TA (1978) Classification of benign diseases associated with prostatic pain: prostatitis or prostatodynia? J Urol 120(2):266. https://doi.org/10.1016/ s0022-5347(17)57135-9

3. Gudaru K, Blanco LT, Castellani D, Santamaria HT, Pelayo-Nieto M, Linden-Castro E, Wroclawski ML, Bellote MC, Inarritu JM, da Silva RD, Gauhar V, Adwin Z, Teoh JY (2019) connecting the 
urological community: the \#UroSoMe experience. J Endoluminal Endourol 2(2):320-e329. https://doi.org/10.22374/jeleu.v2i2.44

4. Grinberg K, Weissman-Fogel I, Lowenstein L, Abramov L, Granot M (2019) How does myofascial physical therapy attenuate pain in chronic pelvic pain syndrome? Pain Res Manag 2019:6091257. https://doi.org/10.1155/2019/6091257

5. FitzGerald MP, Anderson RU, Potts J, Payne CK, Peters KM, Clemens JQ, Kotarinos R, Fraser L, Cosby A, Fortman C, Neville C, Badillo S, Odabachian L, Sanfield A, O'Dougherty B, HallePodell R, Cen L, Chuai S, Landis JR, Mickelberg K, Barrell T, Kusek JW, Nyberg LM, Urological Pelvic Pain Collaborative Research N (2009) Randomized multicenter feasibility trial of myofascial physical therapy for the treatment of urological chronic pelvic pain syndromes. J Urol 182(2):570-580. https://doi.org/10. 1016/j.juro.2009.04.022

6. Magistro G, Wagenlehner FM, Grabe M, Weidner W, Stief CG, Nickel JC (2016) Contemporary management of chronic prostatitis/chronic pelvic pain syndrome. Eur Urol 69(2):286-297. https:// doi.org/10.1016/j.eururo.2015.08.061

7. Franco JV, Turk T, Jung JH, Xiao YT, Iakhno S, Tirapegui FI, Garrote V, Vietto V (2019) Pharmacological interventions for treating chronic prostatitis/chronic pelvic pain syndrome.
Cochrane Database Syst Rev 10:CD012552. https://doi.org/10. 1002/14651858.CD012552.pub2

8. Zhou Z, Hong L, Shen X, Rao X, Jin X, Lu G, Li L, Xiong E, Li W, Zhang J, Chen Z, Pan J, Song B (2008) Detection of nanobacteria infection in type III prostatitis. Urology 71(6):1091-1095. https://doi.org/10.1016/j.urology.2008.02.041

9. Nickel JC, O'Leary MP, Lepor H, Caramelli KE, Thomas H, Hill LA, Hoel GE (2011) Silodosin for men with chronic prostatitis/ chronic pelvic pain syndrome: results of a phase II multicenter, double-blind, placebo controlled study. J Urol 186(1):125-131. https://doi.org/10.1016/j.juro.2011.03.028

10. Zimmermann R, Cumpanas A, Miclea F, Janetschek G (2009) Extracorporeal shock wave therapy for the treatment of chronic pelvic pain syndrome in males: a randomised, double-blind, placebo-controlled study. Eur Urol 56(3):418-424. https://doi.org/ 10.1016/j.eururo.2009.03.043

Publisher's Note Springer Nature remains neutral with regard to jurisdictional claims in published maps and institutional affiliations. 